\title{
Interdisciplinary Insight on European Spruce (Picea abies): Bi- ologically Active Compounds and their Usage
}

\author{
Jeran $\mathbf{M}^{1,2, *}$, Pečan $\mathrm{LI}^{3}$, Barrios-Francisco $\mathbf{R}^{4}$ \\ 1. University of Ljubljana, Faculty of Health Sciences, Laboratory of Clinical Biophysics, Ljubljana, Slovenia \\ 2. University of Ljubljana, Faculty of Electrical Engineering, Laboratory of Physics, Ljubljana, Slovenia \\ 3. University of Ljubljana, Biotechnical Faculty, Department of Biotechnology, Ljubljana, Slovenia \\ 4. Tecnológico Nacional de México/TES de San Felipe del Progreso, División Ingeniería Química, San Felipe del Progreso, Mexico \\ * Correspondence: Marko Jeran; marko.jeran@fe.uni-lj.si
}

Citation: Jeran M, Pečan LI, Barrios-Francisco R. Interdisciplinary Insight on European spruce (Picea abies): Biologically Active Compounds and their Usage. Proceedings of Socratic Lectures. 2021; 6 : 64-70.

https://doi.org/10.55295/PSL.2021.D. 009

Publisher's Note: UL ZF stays neutral with regard to jurisdictional claims in published maps and institutional affiliations.

Copyright: (c) 2021 by the authors. Submitted for possible open access publication under the terms and conditions of the Creative Commons Attribution (CC BY) license

(https://creativecommons.org/licenses/b $\mathrm{y} / 4.0 /)$.

\begin{abstract}
:
Plants have the incredible ability, throughout their developmental cycle, to synthesize the active compounds on which today's drugs and therapies are based. They are also able to synthesize compounds that protect them from outside influences (enemies) and release them into individual plant particles to activate them. Many plants are found on European soil, including the European spruce (Picea abies). Among many other important active substances, spruce also contains limonene, which, along with $\alpha$ - and $\beta$-pinene, is the main group of natural monoterpenes. Limonene, which is mainly found in the peels of citrus fruits, is a useful and sought-after compound in various fields due to its properties. In addition to its use in fragrances, flavors, and beverage additives, it is also used in industry as a solvent and cleaning agent. Due to its ecological potential and a broad spectrum of biological activity, it is classified as an extremely promising active ingredient. Due to limonene's known anti-inflammatory and antiviral activity, it also appears to be of interest in the context of the search for potential agents in the fight against SARS-CoV-2.
\end{abstract}

Keywords: natural compounds, European spruce (Picea abies), natural monoterpenes, total phenols, biologically activity 


\section{European spruce (Picea abies)}

The European (Norway) spruce (Picea abies) belongs to the pine family (Pinaceae), which is the most numerous family of conifers, with more than 200 species. Its home is the European mountains of the central and northern regions. It is distributed from southern Scandinavia to the southern parts of the Alps, the Balkans and the Carpathians, where it thrives at altitudes of 600 to 2,000 m above sea level. In Europe it is mostly found in areas that are not optimal for its vitality (Jeran, 2020). Due to human intervention in the environment, it is difficult to determine its natural distribution. Due to its flexibility, it is one of the most numerous tree species in our country. According to the Forestry Administration, the timber stock in Slovenia for 2019 is 30.4\%. As elsewhere in Europe, we can find spruce frequently even in lower altitudes due to artificial establishment. Spruce is a monoecious plant, which means that both male and female flowers are produced on the same plant. The male flowers are located on the shoots of the last season, are yellow-brown or yellowred in colour in the middle and upper part of the crowns and reach a length of about $3 \mathrm{~cm}$. The female flowers are in an inflorescence and are bright red. Initially they are erect, as they grow, they become $2-4 \mathrm{~cm}$ long and develop into cylindrical, pendulous cones. Unlike the male flowers, which are found in the above-mentioned canopy, the female flowers are only found at the top of the canopy (Jeran et al., 2021).

The spruce is a versatile plant. Its light-coloured, relatively light and soft wood is used mainly in construction, in the furniture and paper industries, and in the manufacture of musical instruments. Many preparations made from spruce wood are also used for medicinal purposes. Of particular note are the essential oils of the needles and the resin in ointments, and the needles and tops are especially useful in the preparation of teas, baths, and vitamin drinks (Jeran, 2020). The active ingredients contained in spruce are said to facilitate the expectoration of mucus in colds, kill bacteria and relieve rheumatism. Ointment made from spruce resin is effective for frostbite and rheumatic pains. From the folk tradition, among the medicinal preparations, the most famous is spruce syrup, prepared by generations to relieve colds and flu in winter. In spring, we harvest the buds, which are up to $2.5 \mathrm{~cm}$ long (by then they contain most of the active ingredients), and put them in a glass jar, which we fill in layers with sugar or honey. Then we put the jar in a warm place (e.g., on a sunny windowsill) for about three weeks. After the elapsed time, we mix the contents well and filter (filtrate). Thus ready, store the syrup in a cool place until use (Jeran, 2020).

\section{Biologically active compounds in European spruce (Picea abies)}

The bark of conifers contains large amounts of lipophilic extractives. In spruce, fatty/resin acids, sterols, and triterpenoids are the most abundant extracts in the inner and outer bark. Spruce bark is also known to be a rich source of phenolic extracts, terpenes, resin acids, flavonoids, stilbenes and stilbene glucosides, lignin and holocellulose. Spruce bark is a source of $\beta$-sitosterol and methyl dehydroabietate, which have antibacterial and antioxidant properties. Stilbenes from spruce bark extracts are also known for their potent antioxidant properties. Tannins from the bark of conifers are used in the manufacture of foams, in medicine, in cosmetics, and in sewage treatment. In addition, raw or extracted bark can be used as an absorbent, and spruce bark has been suggested as a potential feedstock for the production of ethanol from lignocellulose (Bukhanko et al., 2020).

Needles contains mono- and sesquiterpenes, fatty acids, phenolic compounds, stilbene glucosides, waxes and carbohydrates as well as long-chain alcohols, e. g. nonacosan-10-ol, which has superhydrophobic properties (Bukhanko et al., 2020).

The twigs of spruce contain branches that contain resin acids and lignans. However, the content of lignans in the twigs is much lower than in the branches. This gives it potential for use in the manufacture of surfactants, paints, personal care products, cosmetics, and adhesives, as well as a potential raw material for the manufacture of antioxidants (Bukhanko et al., 2020). 


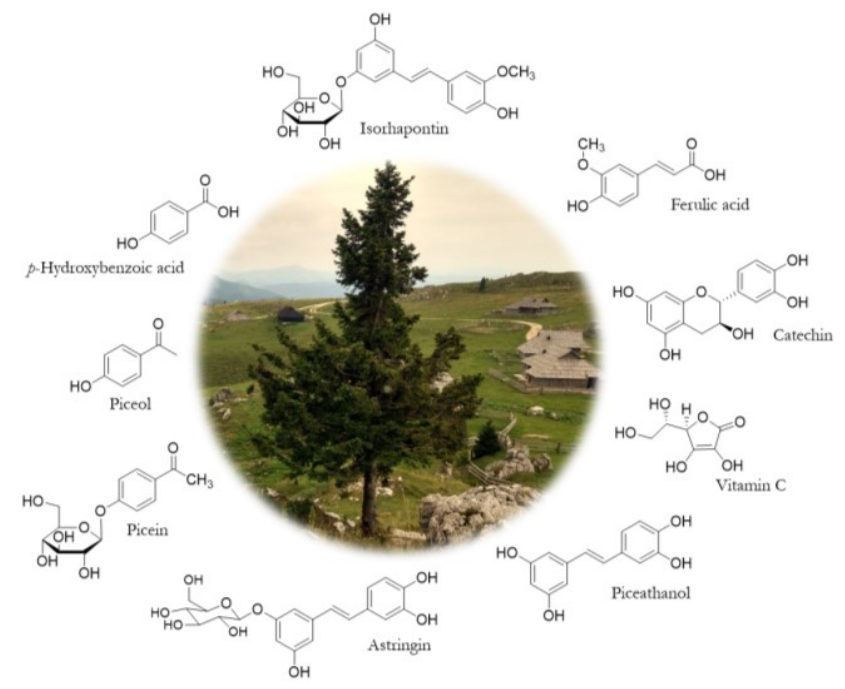

Figure 1. Example of structures of biologically active compounds in European spruce (middle part of the photo: European spruce on the Slovenian plateau Velika planina). From (Jeran et al., 2021).

Polyphenols are compounds with one or more hydroxyl groups attached to the benzene ring, which give them the ability to capture free radicals, moreover it gives them a stronger acidic character in comparison to other alcohol groups. This chemical reactivity is responsible for the antioxidant character of polyphenols. Nisca et al. have found a strong correlation between the antioxidant capacity and content of total polyphenols using ultrasound assisted extraction (UAE) and microwave assisted extraction (MAE). Results also suggested that higher polyphenolic content may lead to a stronger antioxidant activity (Nisca et al., 2021).

The bark of woody vascular plants is often considered a forest waste, but it can be an important source of bioactive compounds with a high potential for capitalisation. The large number of publications regarding the analysis of phenolic compounds extracted from the bark of woody vascular plants is testament to their importance and their value. Consequently, biologically active compounds obtained from the bark of woody plants could be exploited on an industrial scale (Tanase et al., 2019).

Several studies that the best results in terms of total phenolic compounds and antioxidant capacity were obtained for ultrasound assisted extraction (UAE) extract. In study conducted by Spinelli et.al (2021) UAE extract exerted the maximum phenolic concentration among the various green techniques adopted (54.97 $\pm 2.00 \mathrm{mg}$ GAEs/g dray weight). The literature also confirms that UAE applied to various natural matrices significantly increases the phenolic compounds extracted, compared with alternative extraction methods. As a fact, the production of cavitation bubbles promotes better extraction yield and increases the antioxidant activity of these extracts (Spinelli et al., 2021).

We will further focus on the properties of limonene, which, along with $\alpha$ - and $\beta$-pinene, the main group of monoterpenes of European spruce (Picea abies).

\section{Limonene}

\subsection{Chemical background}

Limonene is a liquid, colorless hydrocarbon named after the lemon. It is present in lemon peels and lupins of other citrus fruits in considerable quantities and gives them a characteristic odor. Limonene is an optically active compound and occurs in two enantiomeric forms: the $R$ - and $S$ - forms. The forms differ in source, odor, and taste (Jeran et al., 2021). The enantiomers have the same chemical and physical properties but differ only in the direction of rotation of the plane of linearly polarized light. The enantiomer in solution rotates the plane of polarized light to the right and the other to the left. For ex- 
ample, a chiral molecule that rotates the light to the right is called "right-handed". Some chemical differences between different isomers occur in the presence of other molecules (Barkel, 2012). Despite their physicochemical similarity, they can have different enantiomers that differ significantly in their biological activity. For example, in biochemistry, different enantiomers adapt differently to different enzymes, which explains why they often taste and smell differently and act differently as drugs (Barkel, 2012).

The $R$-(+)-enantiomer of limonene, also known as D-limonene, is the main compound in the essential oils of citrus peels (Citrus spp.). It is also widely present in some species of shrubs (Lippia) and wormwood (Artemisia) (Erasto et al., 2008). The S-limonene form is commonly found in essential oils of the genus Pinus (e.g., pine needles) and the genus Mentha (e.g., meta-spearmint). When both enantiomers of the chiral active ingredient are present in the mixture in equal amounts (in a 1:1 ratio), such a mixture is not optically active and is often referred to in chemistry as a racemic mixture or racemate. The limonene racemate is called dipentene (Jeran et al., 2021).

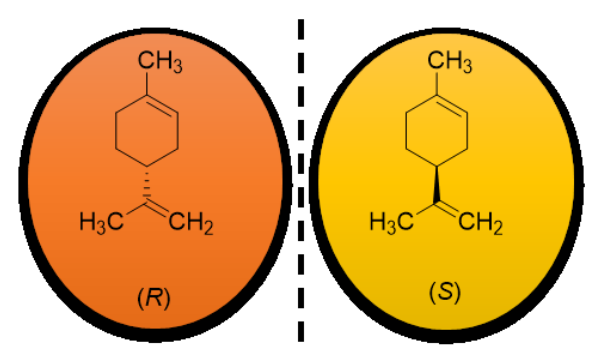

Figure 2. The monocyclic terpene limonene is named 1-methyl-4-(1-methyletenyl)cyclohexene according to IUPAC nomenclature. The figure shows the skeletal form of its enantiomeric forms.

Table 1. Physical properties of limonene. Adapted from: Gupta et al. (2021).

\begin{tabular}{|l|l|}
\hline Molecular formula & C10H16 \\
\hline Molecular weight & 136.24 \\
\hline State at room temperature & Colorless liquid \\
\hline Melting point & $-73.3 \mathrm{oC}$ \\
\hline Density & $175.5-176 \mathrm{oC}$ \\
\hline Solubility & $\begin{array}{l}\text { Slightly soluble in water at } 25 \mathrm{oC}: 13.8 \mathrm{mg} / \mathrm{L} . \text { Moderately soluble in acetone, } \\
\text { dimethyl sulfoxide, ethanol, benzene, carbon tetrachloride, diethyl ether, } \\
\text { petroleum ether }\end{array}$ \\
\hline Storage & $\begin{array}{l}\text { Away from light and air. It forms various oxidation products with atmospheric } \\
\text { oxygen, such ascarvone, limonen oxyde, carveol and limonene hydroperoxides }\end{array}$ \\
\hline
\end{tabular}

Limonene is liquid at room temperature and has proved to be a versatile solvent in the course of the development of its use. Its nonpolar nature shows an affinity for fats, which is why it has been used as an industrial detergent for over thirty years. An important advantage is that it is non-toxic, so it can easily be substituted for toxic and banned solvents such as methyl ethyl ketone (MEK), xylene (dimethylbenzene) and hydrofluorocarbons (CFCs). Its advantages also include biodegradability - it can be broken down relatively quickly to carbon dioxide and water - and the ability to be isolated from renewable sources. It is mainly obtained as a by-product from the processing of citrus peels, from which the lemon is then distilled. Such an isolated lemon is suitable for both technical purposes and for use in food. The essential oil from orange peel obtained by such a process contains $99 \%$ by weight of limonene (Burnham, 2008).

Limonene is used in many products as a flavoring and fragrance, for example in perfumes, beverages, detergents and soaps. In the field of synthesis and processing, it is used as a starting material for the production of various natural products and also plays an important role in the production of $p$-cymene (Erasto et al., 2008). The compound $p$-cymene is used as a drug to prevent cough and to loosen phlegm and is also present as a reagent in the synthesis of pesticides and fungicides16. The US Food and Drug Ad- 
ministration classifies it in the "GRAS" category, which is generally recognized as safe (Marchese et al., 2017).

\subsection{Biological activity of limonene}

The widespread use of limonene in soft drinks, cosmetics, and other products has stimulated research into its potential antitumor and antimicrobial properties (Erasto et al., 2008). It is also known as a natural insecticide used to control pests and prevent spoilage of stored products (Erasto et al., 2008). The advantage of limonene over synthetic pesticides is its biodegradability, which is why it is considered "green" or environmentally friendly. Its pharmacological properties, low toxicity and allergenicity open the possibility of its use in various medicinal and cosmetic products. The content of limonene should be stated on if it is above $0.01 \%$ on the products that are washed-off (such as shampoos, care balms, etc.) or. $0.001 \%$ in products intended for direct application on the body surface (such as varnishes, creams, make-up, etc.) (Erasto et al., 2008).

The chemopreventive properties of limonene have also been studied in various types of cancer (Erasto et al., 2008). Cancer chemoprevention involves various dietary or pharmacological preparations with which we aim to prevent or inhibit the process of tumor development, even before the disease becomes clinically manifest. This requires the effective use of compounds that inhibit specific molecular steps of carcinogenesis at the developmental stage (Jiang, 2018). Consumption of limonene in rodents has been shown to inhibit the development of skin and lung cancer as well as stomach cancer (Erasto et al., 2018 \& Abiodun Elegbede et al., 1986).

Nowadays, the biggest problem is the power of microorganisms against various known antimicrobial agents. One of the mechanisms of action is biofilm formation. Agents that inhibit biofilm production (including limonene) are therefore under intense investigation as possible alternative therapeutics (Gupta et al., 2021). Limonene has been shown to be an effective inhibitor of biofilm of B. cereus, E. coli, P. putida and P. anomala (Gupta et al., 2021). At a concentration of $400 \mu \mathrm{g} / \mathrm{mL}$, about $75-95 \%$ inhibition of biofilm growth was observed against S. pyogenes, S. mutans and S. mitis (Kerekes et al., 2013), and the resulting biofilm mass was reduced by up to $90 \%$ after 8 hours of incubation in 2000 $\mu \mathrm{L} / \mathrm{L}$ for different strains. S. aureus (Espina et al., 2018). Further studies with limonene also showed effective biofilm inhibition against $P$. aeruginosa, $C$. albicans and C. parapsilosis (Gupta et al., 2021; Pekmezovic et al., 2016). The effect of limonene on S. mutans biofilm was also demonstrated in silico studies, making it a suitable candidate for studying these properties (Gupta et al., 2021 \& Nosrati et al., 2018).

\subsection{Limonene and SARS-CoV-2 virus}

Viruses cause many life-threatening diseases. Although many drugs have been developed against viruses in the past, their action has caused many side effects. Therefore, antiviral agents are still being developed and improved. Recent studies on limonene suggest that it may also be of interest in the current epidemic/pandemic (Gupta et al., 2021). In addition to the influenza virus and several other viruses, limonene has been identified as an inhibitor of the coronavirus SARS (Gupta et al., 2021). The SARS virus specifically binds to protein $S$, an enzyme that converts angiotensin 2 (ACE2). The enzyme ACE2 is found on cell membranes and serves as an entry port for the virus into the host cell (Koren et al., 2021; Kralj-Iglič et al., 2020). In a docking study, it was found that limonene could bind to ACE2 and potentially prevent the virus from entering cells (Abdelli et al., 2021).

\section{Conclusions}

Recent evidence on spruce suggests that it is a "green" source of various natural organic compounds (such as limonene, borneol) (Jeran et al., 2021) and cellular particles associated with extracellular vesicles (Jeran et al, 2021). The interdisciplinary synthesis of knowledge in the field of natural products shows an extraordinary potential for future applications, because nature offers a large number of active compounds. The model of spruce and the active ingredient limonene also covers the vertical aspect of use - from 
industry, education, research to medical applications. Due to the constant development of science, scientists will continue to focus on the mechanism of formation of various active substances in plants and use the knowledge for the benefit of a modern and sustainable society.

Funding: This research was supported by by Slovenian Research Agency through the core foundlings No P3-0388.

Conflicts of Interest: The authors declare no conflict of interest.

\section{References}

1. Abdelli I, Hassani F, Bekkel Brikci S, Ghalem S. In silico study the inhibition of angiotensin converting enzyme 2 receptor of COVID-19 by Ammoides verticillata components harvested from Western Algeria. J Biomol Struct Dyn. 2021; 39(9): 3263-3276. DOI: 10.1080/07391102.2020.1763199

2. Abiodun Elegbede J, Elson CE, Tanner MA, Qureshi A, Gould MN. Regression of rat primary mammary tumors following dietary d-limonene. JNCI. 1986; 76(2): 323-325. DOI: 10.1093/jnci/76.2.323

3. Bukhanko N, Attard T, Arshadi M, Eriksson D. Extraction of cones, branches, needles and bark from Norway spruce (Picea abies) by supercritical carbon dioxide and soxhlet extractions techniques. Ind Crop Prod. 2020; 145: 112096. DOI: 10.1016/j.indcrop.2020.112096

4. Burnham PM, Limonene - the industrial degreasing agent found in orange peel (molecule of the month - March 2008). 2008; 1-2. DOI: https://doi.org/10.6084/m9.figshare.5427154

5. Erasto P, Viljoen AM. Limonene - a review: Biosynthetic, ecological and pharmacological relevance. Nat Prod Commun. 2008; 3(7): 1193-1202. DOI:10.1177/1934578X0800300728

6. Espina L, Pagán R, López D, García-Gonzalo D. Individual constituents from essential oils inhibit biofilm mass production by multi-drug resistant Staphylococcus aureus. Molecules. 2015; 20(6): 11357-11372. DOI:

https://doi.org/10.3390/molecules200611357

7. Gupta A, Jeyakumar E, Lawrence R. Journey of limonene as an antimicrobial agent. J Pure Appl Microbiol. 2021; 15(3): 1094-1110. DOI: 10.22207/JPAM.15.3.01

8. Jeran M, Barrios-Francisco R, Kralj-Iglič V. Biološko aktivne učinkovine v navadni smreki (Picea abies): Razumevanje kemijskih lastnosti limonena pri njegovi uporabi in vsestranski biološki aktivnosti. Kemija v šoli in družbi. 2021; 1: 1-6. ISSN 2385-989X. Availabe from https://www.kemija.net/clanek/1755

9. Jeran M, Barrios-Francisco R, Sedušak Kljakič A, Remškar H, Non-destructive characterisation of natural ma-terials: quantitative determination of borneol and limonene in European spruce needles (Picea abies) by FTIR spectroscopy. In Kralj-Iglič V, editor. Socratic lectures: 4th International Minisymposium. Ljubljana, Slovenia, University of Ljubljana, Faculty of Health Sciences. 2021; pp. 79-86. ISBN 978-961-7112-02-3. Available from

https://www.zf.uni-lj.si/images/stories/datoteke/Zalozba/Sokratska_2021.pdf

10. Jeran M, Božič D, Novak U, Hočevar M, European spruce (Picea abies) as a possible sustainable source of cellu-lar vesicles and biologically active compounds. In Kralj-Iglič V, editor. Socratic lectures: 5th International Min-isymposium. Ljubljana, Slovenia, University of Ljubljana, Faculty of Health Sciences. 2021; pp. 104-113. ISBN 978-961-7112-05-4. Available from https://www.zf.uni-lj.si/images/stories/datoteke/Zalozba/Sokratska_5.pdf

11. Jeran M. Navadna smreka (Picea abies) kot vir aktivnih učinkovin. Trdoživ: Bilten slovenskih terenskih biolo-gov in ljubiteljev narave. 2020; 9(2): 22-24. ISSN 2232-5999. Available from: https://issuu.com/trdoziv/docs/trdoziv18_web_v01

12. Jiang X, Liu Y, Ma L, Ji R, et al. Chemopreventive activity of sulforaphane. Drug Des Devel Ther. 2018; 12: 2905-2913. DOI: 10.2147/DDDT.S100534

13. Kerekes E-B, Deák É, Takó M, Tserennadmid R, et al. Anti-biofilm forming and anti-quorum sensing activity of selected essential oils and their main components on foodrelated micro-organisms. J Appl Microbiol. 2013; 115(4): 933-942. DOI: 10.1111/jam.12289

14. Koren J, Scott D, Jeran M, Renin-angiotensin system inhibitors and their implications for COVID-19 treatment. In Kralj-Iglič V, editor. Socratic lectures: 5th International Minisymposium. Ljubljana, Slovenia, University of Ljubljana, Faculty of Health Sciences. 2021; pp. 115-123. ISBN 978-961-7112-05-4. Available from https://www.zf.uni-lj.si/images/stories/datoteke/Zalozba/Sokratska_5.pdf

15. Kralj-Iglič V, Dahmane R, Griessler Bulc T, Trebše P. From extracellular vesicles to global environment: a cos-mopolite Sars-Cov-2 virus. Int J Clin Stud Med Case Reports. 2020; 4(1): 1-23. DOI: 10.46998/IJCMCR.2020.04.000079

16. Marchese A, Arciola CR, Barbieri R, Silva AS, et al. Update on monoterpenes as antimicrobial agents: A partic-ular focus on p-cymene. Materials. 2017; 10(8): 947. DOI: https://doi.org/10.3390/ma10080947 
17. Nisca A, Ștefănescu R, Stegăruș DI, Mare AD. Phytochemical profile and biological effects of spruce (Picea abies) bark subjected to ultrasound assisted and microwave-assisted extractions. Plants. 2021; 10(5): 870. DOI: https://doi.org/10.3390/plants10050870

18. Nosrati M, Behbahani M, Mohabatkar H, Shakeran Z. Antibacterial and antibiofilm activities of Prangos acaulis Bornm. extract against Streptococcus mutans: an in silico and in vitro study. J Herbmed Pharmacol. 2018; 7(3): 176-184. DOI: 10.15171/jhp.2018.29

19. Pekmezovic M, Aleksic I, Barac A, Arsic-Arsenijevic V. Prevention of polymicrobial biofilms composed of Pseudomonas aeruginosa and pathogenic fungi by essential oils from selected Citrus species. FEMS Immunology \& Medical Microbiology. 2016; 74(8): ftw102. DOI: 10.1093/femspd/ftw102

20. Spinelli S, Costa C, Conte A, La Porta N, et al. Bioactive compounds from Norway spruce bark: Comparison among sustainable extraction techniques for potential food applications. Foods. 2019; 8(11): 524. DOI: https://doi.org/10.3390/foods8110524

21. Tanase C, Coșarcă S, Muntean D-L. A critical review of phenolic compounds extracted from the bark of woody vascular plants and their potential biological activity. Molecules. 2019; 24(6): 1182. DOI: https://doi.org/10.3390/molecules24061182

22. van Brakel J, Substances: The ontology of chemistry. In Woody AI, Findlay HendryR, Needham P, editors. Phi-losophy of chemistry. North Holland, The Nederlands, Elsevier. 2012; pp. 191-229. DOI: 10.1016/B978-0-444-51675-6.50018-9 